ARTIGO ORIGINAL

\title{
MÉTODOS DE PESQUISA PARA ADMINISTRAÇÃO: INVESTIGAÇÕES DE SHERLOCK HOLMES
}

\section{RESEARCH METHODS FOR MANAGEMENT: SHERLOCK HOLMES INVESTIGATIONS}

Aline Vieira Malanovicz ${ }^{1}$

\begin{abstract}
Resumo
O objetivo desta pesquisa é identificar "pistas" de recomendações de métodos de pesquisa úteis para Administração relatados como métodos de investigação utilizados pelo personagem Sherlock Holmes. A pesquisa é qualitativa, exploratória e descritiva, e consiste na consulta bibliográfica ao cânone de obras narrativas de Sir Arthur Conan Doyle, protagonizadas pelo célebre detetive (quatro romances e cinco livros com 56 contos). Os resultados desta pesquisa são trechos ilustrativos de métodos utilizados por Sherlock Holmes, e a análise de dados os coteja com métodos recomendados em artigos e livros-textos reconhecidos da área de Métodos de Pesquisa em Administração. Este panorama oferece amplo potencial para complementar e auxiliar o processo de ensino-aprendizagem, apresentando outro olhar sobre metodologias de pesquisa e reforçando a importância do rigor metodológico no uso de técnicas de coleta e análise de dados em Administração.
\end{abstract}

Palavras-chave: Métodos de Pesquisa; Literatura e Gestão; Literatura; Sherlock Holmes.

\begin{abstract}
The purpose of this research is to identify "clues" to recommendations of useful research methods for Management reported as research methods used by the Sherlock Holmes character. The research is qualitative, exploratory and descriptive, and consists of the bibliographical consultation to the canon of narrative works of Sir Arthur Conan Doyle, carried out by the famous detective (four novels and five books with 56 stories). The results of this research are illustrative excerpts of methods used by Sherlock Holmes, and the data analysis matches them with methods recommended in articles and recognized textbooks of the area of Methods of Research in Management. This panorama offers broad potential to complement and assist the teaching-learning process, presenting another look at research methodologies and reinforcing the importance of methodological rigor in the use of data collection and analysis techniques in Management.
\end{abstract}

Key-words: Research Methods; Literature and Management; Sherlock Holmes.

\footnotetext{
${ }^{1}$ Doutora em Administração (Sistemas de Informação) pela UFRGS. E-mail: malanovicz@gmail.com
}

Artigo recebido em: 30 de junho de 2018. Artigo aceito em 18 de dezembro de 2019. 


\section{Introdução}

Para o desenvolvimento e aplicação de pesquisas do campo de conhecimento da Administração, assim como para a maturidade da área como ciência propriamente dita, um tema de investigação relevante são os desafios da apropriação e do ensino de Métodos de Pesquisa. Os principais eventos científicos da área dedicam temas de interesse específicos para Estratégias e Métodos de Pesquisa Quantitativos e Qualitativos (EnANPAD, 2018). É possível perceber o potencial de contribuição de abordagens de outras áreas do conhecimento, como as Ciências Humanas e Sociais, e os relacionamentos possíveis da Administração com as Artes, incluindo a Literatura (PINHEIRO; VIEIRA, 2008). Essas áreas têm potencial para oferecer vínculos úteis para a compreensão de diferentes temas relativos aos métodos de pesquisa. O contato entre variadas áreas de conhecimento pode proporcionar a superação de estereótipos em torno dos campos de saber e ampliar as suas possibilidades de exercício, além de constituir apoio valioso para o processo de ensino-aprendizagem do tema (ALVES, 2007).

Em artigos científicos publicados por docentes das áreas de Gestão e Estudos Organizacionais, existem relatos de iniciativas de utilização de obras literárias como instrumento de ensino e como atividade auxiliar para complementar a compreensão de determinados tópicos (PINHEIRO; VIEIRA, 2008). Seguindo esse exemplo, explora-se aqui o uso de Métodos de Pesquisa, enfatizado pela existência de muitas narrativas presentes em obras da Literatura (especialmente da chamada literatura policial) que remetem de imediato a situações habitualmente reconhecidas como uso de métodos de investigação. O foco aqui está nas narrativas de Sir Arthur Conan Doyle (1859-1930), cujo protagonista é Sherlock Holmes.

O objetivo desta pesquisa é, portanto, identificar "pistas" de recomendações de métodos de pesquisa úteis para Administração relatados como métodos de investigação utilizados pelo personagem Sherlock Holmes.

Este artigo se estrutura como segue. Apresenta-se um referencial incluindo métodos de pesquisa em Administração, conexões entre Literatura e Metodologia de Pesquisa, e contextos das histórias de Sherlock Holmes. Em seguida, apresenta-se o Método utilizado neste trabalho, assim como os Resultados da pesquisa, com sua Discussão, e a seção de Conclusões.

\section{Métodos de Pesquisa em Administração, Literatura e Sherlock Holmes}




\section{MALANOVICZ}

Os Métodos de Pesquisa científica úteis para Administração podem ser identificados nas obras de referência de cursos de Metodologia de Pesquisa oferecidos pelos Programas de Pós-Graduação em Administração. Por isso, a breve exposição que segue tem como base a bibliografia, repleta de obras "clássicas", dos planos de ensino de disciplinas desses cursos (da UFRGS), como Gerência de Serviços, Métodos Qualitativos, Pesquisa Qualitativa.

- Elaboração de ensaios teóricos (SUTTON; STAW, 2003)

Defesa de argumentos teóricos que desenvolvam a ciência nesta área do conhecimento

- Pesquisa survey (FREITAS et al., 2000; HAIR et al., 2005; MALHOTRA, 2006)

Questionários com grande número de respondentes para testar hipóteses

- Métodos de Pesquisa Operacional (MEREDITH et al., 1989)

Modelagem quantitativa de cargas e fluxos de operações de serviços

- Método experimental (CAMPBELL; STANLEY, 1979)

Verificação de relações de causalidade, com grupo-foco e grupo-controle

- Pesquisa-ação (STRINGER, 2007; THIOLLENT, 2003; VERGARA, 2004)

Intervenção nas organizações para diagnóstico e resolução de problemas

- Métodos qualitativos em geral (DENZLIN; LINCOLN, 1994; CARDOSO, 1986)

Pertinentes para pesquisas em Serviços, cuidando-se o rigor metodológico

- Estudos de caso (YIN, 2015; DUBÉ; PARÉ, 2003; STAKE, 2005)

Questões "como e por quê" em fenômenos do presente em contextos reais

- Técnica entrevista (BRYMAN; CASSEL, 2006; RAPLEY, 2004; SPRADLEY, 1979)

Obtém a percepção, opinião e inferências dos sujeitos sobre o tópico-foco

- Técnica Focus Group (MacNAGHTEN; MYERS, 2004)

Obtém as percepções e o debate de opiniões de vários sujeitos (stakeholders)

- Técnica de pesquisa documental (PRIOR, 2004)

Obtém registros de eventos, estruturas, situações (correspondências, atas...)

- Técnica de observação participante (SERVA; JAIME, 1995; TEDLOCK, 2003)

Obtém percepções de comportamentos e razões no contexto de eventos reais

- Análise de dados (especificamente Análise de Conteúdo) (BARDIN, 2004).

Validação de inferências para um contexto, segundo componentes e relações

Quanto às aproximações entre Literatura e Metodologia de Pesquisa, pode-se dizer que "A pesquisa é sempre uma aventura nova sobre a qual se deve refletir" (CARDOSO, 1986), e "Toda obra literária é essencialmente uma pesquisa" (Beauvoir apud FISCHER et al., 2006). As aproximações entre Literatura e Metodologia de Pesquisa brevemente expostas a seguir baseiam-se na obra de Pinheiro e Vieira (2008). Os autores defendem que, do mesmo modo que na escrita literária, a escrita de artigos científicos é guiada por uma efetiva estratégia de convencimento para envolver e 


\section{MALANOVICZ}

persuadir os leitores, no caso, quanto aos nexos entre a teoria e os resultados que estão sendo demonstrados e defendidos no trabalho (PINHEIRO; VIEIRA, 2008).

A estratégia narrativo-descritiva, utilizada na Literatura e na Pesquisa (na escrita de artigos científicos), inclui, em regra, a descrição minuciosa de tempo e espaço, ambiente e cenários (por exemplo, a organização, estruturas, costumes), descrição e perfil psicológico dos personagens (clientes, fornecedores, funcionários), e a teia de relações que conecta a todos, com o enredo, ou os eventos que compõem as rotinas administrativas ou os processos de serviços, transportando o leitor para dentro da "alma" do tema de estudo.

Muitos textos literários podem ser apreciados como efetivos estudos de caso descritivo-explicativos sobre fatos do passado e do presente. A maioria das narrativas responde às clássicas perguntas exigidas dos estudos de caso: "como?" e "por quê?" (YIN, 2015), além de fazer isso a partir de múltiplas fontes de dados, como descrições do ambiente, depoimentos de personagens e narrativas de fatos ocorridos, assemelhando-se, também por isso, ao estudo de caso como procedimento metodológico (PINHEIRO; VIEIRA, 2008).

Diferentes experiências de ensino na área de Gestão com utilização de obras literárias como material de apoio e complemento são relatadas por Pinheiro e Vieira (2008). Um exemplo referenciado é a opção de uso do livro A Arte Cavalheiresca do Arqueiro Zen, de Eugen Herrigel, para a disciplina Métodos de Pesquisa. Outro exemplo é a utilização de textos Terra Molhada de Siena, do livro A Bagagem do Viajante, de José Saramago, em aulas de Pesquisa em Administração para mestrado de Baêta (2007). Destaca-se a analogia entre diversos trechos da obra e as etapas de um projeto de pesquisa científica, permitindo que a leitura e a discussão do texto cubram desde a formulação da questão de pesquisa, o delineamento de uma estratégia de investigação, até a obtenção e análise dos resultados.

Fischer et al. (2006) abordam a pesquisa em organizações e o uso de textos literários na produção do conhecimento. Afirmam que a literatura tem adeptos entre os pesquisadores como recurso de investigação (a escrita em forma de narrativa, e as narrativas literárias que podem servir à pesquisa), e destacam que a literatura tem sido usada com crescente entusiasmo no ensino de Administração, mas é um campo pouco explorado no Brasil.

Nesse sentido, cabem algumas reflexões sobre os paralelos entre a literatura e os 


\section{MALANOVICZ}

métodos científicos utilizados para a geração ou comprovação de conhecimentos nos mais diversos campos (PINHEIRO; VIEIRA, 2008). Alves (2007) defende que as relações que se estabelecem entre arte e metodologia da pesquisa, literatura, narrativas, criação estética e redação literária podem agregar significativas novidades ao processo de ensino, pesquisa e formação profissional. Isto é o que se almeja realizar neste trabalho de pesquisa.

O personagem Sherlock Holmes é um Detetive Consultivo que viveu em Londres, na 221B Baker Street, na época Vitoriana, na companhia do seu amigo, Dr. Watson. É um investigador famoso por utilizar o método científico e a lógica dedutiva para a resolução de mistérios, com impressionante capacidade de dedução e senso de observação, e uma variada cultura geral. Auxiliava a Polícia Metropolitana de Londres (Scotland Yard) sempre que era consultado às vezes utilizando métodos pouco ortodoxos (BEST OF SHERLOCK HOLMES, 2010). Sherlock Holmes é a ficção mais famosa em todos os continentes, superando os outros dois de maior renome universal: Robinson Crusoé e Dom Quixote. É o personagem da literatura mundial que recebeu o maior número de adaptações (teatro, cinema, quadrinhos, jogos...), estudos e especulações, inclusive por The Sherlock Holmes Society of London, um clube que se dedica a estudá-lo e mantém o seu museu, localizado em 221B Baker Street, "o endereço mais famoso do mundo" (SHERLOCK HOLMES MUSEUM, 2018).

Sir Arthur Conan Doyle está entre os primeiros escritores de histórias e romances de detetive da Inglaterra. Quando começou a escrevê-los, havia grande demanda por histórias, pois mais pessoas vinham sendo educadas e alfabetizadas, e, assim, atendia à demanda de textos fantásticos de uma cultura de massas nascente (SHERLOCK HOLMES MUSEUM, 2018). Concebeu um “detetive científico" ao criar o personagem Sherlock Holmes, e com ele consolidava um modelo da categoria literária romance policial, de acordo com um otimismo corrente (com relação à ciência e suas descobertas) comum em sua época, a época de Huxley, Tyndall, Darwin, Spencer e Stuart Mill na Inglaterra. Nesse sentido, o personagem veiculava as ideias do autor, impregnadas de valores cientificistas, entre os quais o Positivismo, dominante na sociedade quando as histórias foram criadas (SILVA, 2010).

\section{Procedimentos Metodológicos}

Esta pesquisa caracteriza-se como qualitativa, exploratória e descritiva. O 


\title{
MALANOVICZ
}

método de investigação adotado consiste em um levantamento bibliográfico. O tema da pesquisa é a própria Metodologia de Pesquisa identificada nas investigações de Sherlock Holmes.

- Objeto de Estudo: O corpus da pesquisa, as fontes a serem analisadas, foi delimitado especificamente ao chamado Cânone Sherlockiano: "o conjunto de todas as obras de Sherlock Holmes publicadas por Sir Arthur Conan Doyle; ou seja, os quatro romances e as 56 historietas" (SHERLOCK HOLMES MUSEUM, 2018) (ver ANEXO 1). A escolha do corpus se justifica por motivo de que: "Tudo que sabemos sobre a vida do detetive é proveniente única e exclusivamente do Cânone, sendo esta, portanto, a mais fiel fonte de estudo sobre o universo do Grande Detetive" (SHERLOCK HOLMES MUSEUM, 2018). As obras do Cânone são tradicionalmente identificadas com siglas como segue:

\author{
Romances \\ [STU] A Study in Scarlet (1887) - Um Estudo em Vermelho \\ [SIG] The Sign of Four (1890) - O Signo dos Quatro \\ [HOU] The Hound of the Baskervilles (1902) - O Cão dos Baskervilles \\ [VAL] The Valley of Fear (1915) - O Vale do Terror
}

Livros de contos (ver ANEXO 1 para siglas identificadoras das 56 historietas)

[ADV] Adventures of Sherlock Holmes (1892) - As Aventuras de Sherlock Holmes

[MEM] The Memoirs of Sherlock Holmes (1893) - Memórias de Sherlock Holmes

[RET] The Return of Sherlock Holmes (1905) - A Volta de Sherlock Holmes [BOW] His Last Bow (1917) - O Último Adeus de Sherlock Holmes

[CAS] The Case-Book of Sherlock Holmes (1927) - Histórias de Sherlock Holmes

- Procedimentos de Coleta de Dados: A coleta dos dados incluiu a localização de todos os textos (em português) em livros físicos (optou-se pela coleção de bolso da editora L\&PM), e o download de todos os textos do cânone do website CAMDEN HOUSE (2014) e das citações do website SHERLOCK HOLMES MUSEUM (2018), para um computador pessoal, formando assim um banco de dados coletados, disponível sob consulta. Foi realizada a leitura de todas as narrativas (tanto romances como contos), primeiramente em inglês e depois em português, seguindose o destacamento de todos os trechos (da versão em português) com potencial de revelar recomendações de métodos de investigação pelo Grande Detetive. Para fins 


\section{MALANOVICZ}

de replicabilidade da pesquisa, vale registrar que todas as obras que compõem o Cânone podem ser encontradas em português (editoras Ediouro, Melhoramentos, L\&PM), e em inglês, nos websites citados.

- Procedimentos de Análise de Dados: A análise dos dados consistiu no cotejo de trechos selecionados como ilustração de métodos de pesquisa e de recomendações para garantia do rigor metodológico que são tradicionalmente indicados por artigos científicos e livros-texto reconhecidos da área de Métodos de Pesquisa em Administração.

\section{Resultados e Discussões}

Esta seção apresenta os resultados da pesquisa, comentados, para discussão e análise frente ao referencial teórico dos métodos de pesquisa apresentado na seção 2 deste trabalho. As citações de trechos usam as siglas canônicas das histórias como referência (ANEXO 1).

Em diversas histórias são identificados trechos em que o próprio personagem define a si mesmo e aos seus métodos de investigação. Algumas de suas "máximas" soam claramente como recomendações de rigor metodológico para a pesquisa em Administração.

\footnotetext{
Meu nome é Sherlock Holmes, e é meu dever saber o que os outros não sabem. [BLUE][ADV]

Tenho certa queda tanto para a observação como para a dedução. [STU]

É que sou um leitor único, dotado de uma memória estupenda para reter certos detalhes. [LION][CAS]

Talvez eu me tenha treinado para ver aquilo que os outros olham superficialmente. [IDEN][ADV]

O mundo está cheio de coisas óbvias que por acaso ninguém jamais observa. [HOU]

Você conhece o meu método. É baseado na observação das coisas triviais. [BOSC][ADV]

Há muito tempo tenho por máxima que são justamente as coisas pequeninas que têm maior valor. [IDEN][ADV]

Nunca se fie nas impressões gerais, mas concentre-se nos pormenores. [IDEN][ADV]
}

Uma das recomendações mais frequentes de Sherlock Holmes refere-se à importância dos detalhes. A mesma recomendação pode ser depreendida da leitura de obras sobre Estudo de Caso (YIN, 2015; DUBÉ; PARÉ, 2003) e Observação Participante (TEDLOCK, 2003). "A observação na pesquisa permite ao observador construir uma imagem de lifeworld daqueles que estão sendo observados e um entendimento do modo como eles comumente agem em relação às suas atividades 


\section{MALANOVICZ}

cotidianas" (STRINGER, 2007). Além disso, devem "registrar suas observações como notas de campo, notando especialmente detalhes importantes para formular descrições: lugares, pessoas, objetos, atos, atividades, eventos, propósitos, tempo, sensações" (STRINGER, 2007). Assim como para Sherlock Holmes, notas de campo são o recurso mais comum usado para observações. E hoje em dia videotapes e fotografias podem oferecer poderosos registros de eventos e atividades (BAUER; GASKELL, 2002).

Não há nada como as informações em primeira mão. [STU]

Entre as “informações em primeira mão" valorizadas por Sherlock Holmes, estão os dados provenientes de entrevistas com os participantes do contexto da pesquisa, como enfatizam autores de textos sobre método: "Questões apropriadas permitem aos pesquisadores descrever a situação nos termos dos próprios participantes, quando criam oportunidades de se engajar em entrevistas e conversas que estendem o conjunto de informações disponíveis” (SPRADLEY, 1979). “Tipicamente, empregam-se múltiplos métodos. Idealmente, duas ou mais fontes devem ser usadas. O objetivo é obterem-se dados ricos sobre a questão de pesquisa específica, bem como capturar a complexidade contextual" (BENBASAT et al., 1987).

Uma característica em Sherlock Holmes, importante para seu sucesso, era a de ser um tipo eminentemente urbano e saber tirar partido de tudo o que a vida na cidade poderia oferecer, e que fazia parte da vida de seus leitores (SILVA, 2010). Em suas aventuras ele se vale abundantemente das condições trazidas pela modernidade: os trens, os tílburis de aluguel, o telégrafo e os vários jornais como fonte de informação.

Esse entendimento pode ser constatado em:

\footnotetext{
Não existe conhecimento inútil para um detetive. [VAL]

Um passatempo meu obter um conhecimento exato das ruas de Londres. [REDH][ADV]

Qualquer verdade é melhor do que a dúvida. [YELL][MEM]

Devemos conservar o cerebrozinho em atividade, cheio de todos os elementos que nos possam ser úteis, e o resto podemos guardar na biblioteca, onde o iremos procurar quando necessário. [FIVE][ADV]
}

A importância dos conhecimentos prévios de especialista do pesquisador sobre os temas do estudo de caso é enfatizada na recomendação de que eles devem ser utilizados (YIN, 2015). "No Estudo de Caso, os resultados dependem do poder integrativo do investigador" (BENBASAT et al., 1987). Múltiplos métodos permitem triangulação. Deve-se buscar montar uma clara cadeia de evidências (objetivos, questões, asserções, escolhas de desenho, dados não-cobertos, resultados, conclusões).

Entretanto, uma importante distinção pode ser depreendida dos seguintes 


\section{MALANOVICZ}

trechos:

Enfrentamos o caso com espírito completamente desarmado, o que, nestas circunstâncias, constitui sempre uma vantagem. Não tínhamos formulado nenhuma hipótese. Ali estávamos, simplesmente para observar e tirar conclusões do que nos fosse dado ver. [CARD][BOW]

É arriscado especular antes de ter dados na mão... Inconscientemente começa-se a torcer os fatos para acomodá-los às teorias, em vez de fazer as teorias coincidirem com os fatos. [SCAN][ADV]

Jamais arrisco um palpite. Isso é um hábito chocante... fatal para a capacidade de raciocinar logicamente. [SIG]

Nunca faço exceções. Uma exceção anula a regra. [SIG]

É um grande erro formar teorias antes dos fatos. [SECO][RET]

É um erro capital teorizar antes de possuir todos os indícios; distorce o raciocínio. [STU]

É outra das "máximas" de Sherlock Holmes: não teorizar antes de ter todos os dados. A recomendação se aplica tanto aos métodos chamados quantitativos (pesquisa survey, por exemplo) (FREITAS et al., 2000) quanto aos métodos ditos qualitativos, como o Estudo de Caso, por exemplo:

O Estudo de Caso é próprio para capturar o conhecimento de praticantes e desenvolver-se teoria a partir dele, e requer pouca especificação a priori de variáveis dependentes e suas medições permitem o uso de alto grau de discrição em estruturar e interpretar dados" (BENBASAT et al., 1987).

Destacamos outros trechos:

É da mais alta importância, na arte da dedução, distinguir em determinados fatos os que são incidentais e os que são fundamentais. De outra forma, a energia e a concentração se dissiparão, em vez de se concentrarem. [REIG][MEM]

Essa distinção entre o que é fundamental entre os dados converge com a recomendação de "Habilidades desejáveis para o pesquisador" apresentadas por Yin (2015) e que incluem: "ser capaz de fazer boas perguntas, interpretar as respostas, ser um bom ouvinte, ser adaptável e flexível, ter noção clara das questões que estão sendo estudadas e ser imparcial em relação a noções preconcebidas”. Esta última habilidade pode também ser referenciada à máxima de Sherlock Holmes anteriormente citada de "não teorizar sem ter os dados".

O raciocinador ideal, depois de observar um simples fato em todas as suas facetas, deduz o encadeamento dos acontecimentos e todos os resultados que se seguirão. [CROO][MEM]

Uma conclusão verdadeira sugere sempre outras. [SILV][MEM]

De uma gota de água um raciocinador lógico poderia inferir a possibilidade de um Niágara ou de um Atlântico, sem ter visto ou ouvido um ou outro. Assim, toda a vida é uma grande cadeia cuja natureza se revela ao examinarmos qualquer dos elos que a compõe. [STU]

O observador que compreendeu perfeitamente um elo numa série de incidentes deve ser capaz de prever acertadamente todos os outros pontos relativos ao caso, tanto antes como depois. [FIVE][ADV] 


\title{
MALANOVICZ
}

Nestes trechos, Holmes destaca o processo do encadeamento das inferências a partir das evidências. Nesse sentido, as recomendações para Relatórios de pesquisas (YIN, 2015; DUBÉ; PARÉ, 2003) dizem que é "essencial a manutenção de um encadeamento de evidências", que deve ficar claro: "O leitor deve poder seguir a derivação de qualquer evidência, das questões de pesquisa até às conclusões”, como Watson faz em seus textos.

O método do detetive utilizado por Conan Doyle para uma detecção científica é explicado de acordo com as categorias da Filosofia e dentro das prescrições da Lógica Clássica. O filósofo inglês Peirce (1839-1914) considera que, além da dedução e da indução, há a abdução, que é uma espécie de intuição que não se dá de uma só vez, mas vai indo passo a passo para chegar a uma conclusão. A abdução é a busca de uma conclusão pela interpretação racional de sinais, de indícios, de signos. É a forma que a razão possui quando inicia o estudo de um novo campo científico que ainda não havia sido abordado, como no caso da Ciência de Serviços. O exemplo mais simples oferecido por Peirce para explicar o que seja a abdução são os contos policiais, o modo como os detetives vão coletando indícios ou sinais e formando uma teoria para o caso que investigam (CHAUÍ, 2004).

A autora chama a atenção:

\begin{abstract}
Ao resolver um problema desse gênero, o essencial é saber raciocinar retrospectivamente. $\mathrm{E}$ um processo muito útil, e muito fácil, mas poucos se servem dele. Nos assuntos cotidianos, é mais útil raciocinar para a frente, na direção do tempo, de maneira que o processo inverso vai sendo esquecido. [STU]
\end{abstract}

O método de produzir conhecimento apresentado em suas histórias pode ser considerado um modelo de raciocínio pelo qual se apreendem as possibilidades orientando os vetores intelectuais na direção dos efeitos para as causas, como se fossem profecias retrospectivas e suas histórias simbolizam o saber indiciário ou abdutivo, que se opõe ao Racionalismo puramente dedutivista vigente desde o século XVII (SILVA, 2010). As aventuras de Sherlock Holmes são apresentadas como um modelo de procedimento científico e transparece nelas um espelho da ciência do século XIX (SILVA, 2010).

Nesse sentido histórico, pode-se dizer que as concepções filosóficas e os métodos de Holmes podem ser classificados, quanto ao posicionamento paradigmático e epistemológico, como positivistas ou pós-positivistas. "O positivismo adota uma 


\section{MALANOVICZ}

posição de realismo e confia no pressuposto de um mundo objetivo externo à mente. $\mathrm{O}$ pós-positivismo afirma que a realidade somente pode ser conhecida probabilisticamente" (GEPHART JR, 2004). Outra característica determinante destes dois paradigmas é a de que ambos buscam descobrir "a" verdade ou "a" realidade verdadeira. Esse aspecto fica claro na "máxima" de Holmes mais enfatizada no cânone:

É provérbio meu que, tendo excluído tudo o que é impossível, aquilo que fica, por mais improvável que pareça, é a verdade. [BERY][ADV]

Elimine todos os outros fatores, e o que restar deve ser a verdade. [SIG]

Uma vez eliminado tudo o que é impossível, o restante, por pouco provável que pareça, deve ser a verdade. [BLAN][CAS]

Quantas vezes já lhe disse que, tendo eliminado o impossível, o que lhe restar, por improvável que seja, deve ser a verdade? [SIG]

Não devemos esquecer-nos do velho axioma de que, quando todas as outras hipóteses falham, a que resta, mesmo que seja improvável, deve traduzir a verdade. [BRUC][BOW]

Esta explicação é improvável, mas todas as outras explicações são ainda mais improváveis. [SILV][MEM]

Avaliamos as probabilidades e escolhemos as mais prováveis. Isso é o uso científico da imaginação. [HOU]

Yin (2015) também enfatiza que o relato de pesquisa "deve deixar claro que se baseou em todas as evidências, deve abranger todas as principais interpretações concorrentes, e deve se dedicar aos aspectos mais significativos do caso". "Como as deduções lógicas podem ser obtidas através de proposições verbais, procura-se estabelecer relações entre os modelos conceituais e o comportamento real empírico. Estas deduções devem ser testadas posteriormente" (POZZEBON; FREITAS, 1997).

Assim, as possíveis teorias explicativas concorrentes devem, portanto, ser formuladas e consideradas, sem medo, para então serem submetidas a testes de validade, eliminando-se todas aquelas que revelarem falhas (impossibilidades) na confrontação com os dados.

Este processo oportuniza aos pesquisadores a verificação da veracidade de suas próprias observações. Deduções referentes a propósitos e sentimentos podem ser inferidas apenas superficialmente por um observador e precisam ser verificadas quanto a sua eficácia (SPRADLEY, 1979).

Outras "máximas":

Devemos sempre prever duas hipóteses e tomar precauções contra elas. É a primeira regra, numa investigação. [BLAC][RET]

Watson, o que é preciso é raciocinar. Você é muito tímido e receia errar em suas conclusões. [BLUE][ADV]

Quando um fato parece se opor a uma longa cadeia de deduções, ele invariavelmente se presta a qualquer outra interpretação. [STU]

Prova circunstancial é uma coisa ilusória - respondeu Holmes, pensativo; — pode demonstrar claramente determinado pormenor, mas se você alterar o seu ponto de vista, por pouco que seja, poderá notar que a prova aponta de 


\section{MALANOVICZ}

modo comprometedor numa direção completamente oposta. [BOSC][ADV]

Em qualquer tipo de pesquisa, grande atenção deve ser dada aos fatos que não podem ser explicados pela teoria. Por exemplo, na pesquisa do tipo survey, a presença de outliers (resultados que ficam fora dos intervalos de maior concentração dos dados obtidos) (HAIR et al., 2005) sempre requerem explicação. Do mesmo modo, em pesquisas qualitativas, ocorrências e comportamentos fora do padrão devem ser revistos (DUBÉ; PARÉ, 2003).

Dessa forma, a flexibilidade do pesquisador reveste-se de maior importância, pois, a qualquer momento no decorrer da investigação, “o investigador desenvolve novas hipóteses", e então "mudanças de unidade de análise e de método de coleta de dados podem ser efetuadas" (BENBASAT et al., 1987). Retoma-se, com esta ideia, a recomendação de elaborar outras novas teorias explicativas possíveis, ao perceber-se que as atuais hipóteses de trabalho não explicam satisfatoriamente os fatos.

Entre as "máximas" que Sherlock Holmes adota ao se referir à profissão de investigador, parece válido reunir as seguintes na condição de fechamento desta série de recomendações. Os trechos podem ser vistos como "dicas" para os pesquisadores.

\footnotetext{
Não há limite para a cultura, Watson. Ela constitui uma série de lições, das quais a maior é sempre a última. [REDC][BOW]

Uma visão ampla é uma das coisas essenciais na nossa profissão. $\mathrm{O}$ entrelaçamento de ideias e um cabedal de conhecimentos múltiplos e variados oferecem sempre um extraordinário interesse. [VAL]

Como todas as outras artes, a ciência da dedução e análise só pode ser adquirida por meio de um demorado e paciente estudo, e a vida não é tão longa que permita a um mortal aperfeiçoar-se ao máximo nesse campo. [STU]
}

A "visão ampla" a que Holmes se refere, tão essencial à profissão de investigador (ou pesquisador), pode ser associada à percepção do já referido potencial de contribuição dos relacionamentos possíveis da Ciência de Serviços com as Artes, superando estereótipos e explorando a multidisciplinaridade. Os vínculos identificados nos trechos aqui citados mostram-se úteis para a compreensão de diferentes aspectos dos métodos de pesquisa, o que pode contribuir para desenvolver o processo de ensinoaprendizagem deste tema.

\section{Conclusões}

Esta pesquisa atingiu seu objetivo de identificar "pistas" de recomendações de métodos de pesquisa úteis para Administração relatados como métodos de investigação utilizados pelo personagem Sherlock Holmes. Os resultados deste trabalho reforçam 


\section{MALANOVICZ}

achados de Silva (2010), que deduz certas habilidades recomendadas para detetives (ou, neste caso, para pesquisadores de Administração): capacidade de observação e dedução; raciocínio retrospectivo, analítico; conhecimentos específicos sobre o tema envolvido no caso em estudo; imaginação para alternativas de estratégia de investigação; paciência e prudência de não teorizar sem ter todos os indícios possíveis; separar o essencial do acidental; eliminar tudo o que é impossível; criar hipóteses que deverão ser provadas.

Entre os métodos utilizados por Sherlock Holmes que também são úteis para a pesquisa em Administração, destacam-se o Estudo de Caso com técnicas de Observação e Entrevistas. Pode-se dizer que os próprios relatos de Watson a respeito das aventuras de seu amigo Sherlock Holmes se assemelham a relatos de estudo de caso, a partir de múltiplas fontes de dados, como descrições do ambiente, depoimentos de personagens, e narrativas de fatos ocorridos. Além disso, destaca-se nas recomendações do detetive a importância quanto à análise de dados e à elaboração de teorias explicativas. $\mathrm{O}$ rigor lógico e metodológico recomendado para a validade das inferências obtidas dos dados ecoa das "máximas" do Grande Detetive em todos os aspectos de uma investigação.

Entre essas máximas enfatizadas pelo personagem ao longo das histórias do cânone a mais repetida é: "eliminando o impossível, o que resta, mesmo que pouco provável, deve ser a verdade", com forte referência ao Positivismo. Além desta, podem ser destacadas outras recomendações de rigor metodológico, essenciais para a arte da investigação em diversas áreas do conhecimento: "observar os detalhes, as coisas triviais", "não formar teorias antes dos fatos e indícios, para não distorcer o raciocínio, nem torcer os fatos para acomodá-los às teorias", "demonstrar todo um encadeamento de inferências, desde as evidências, fatos e indícios, até a teoria que explica todos eles".

Este trabalho procura reforçar a ideia de que o rigor metodológico aplicado no uso de técnicas de coleta e análise de dados, a correta proposição de questões e problemas de pesquisa, são questões essenciais da área de Metodologia de Pesquisa. Acredita-se que o panorama apresentado oferece amplo potencial para auxiliar e complementar o processo de ensino-aprendizagem para o rigor da aplicação de métodos de pesquisa na Administração.

Pesquisas futuras semelhantes poderiam investigar os métodos de outros detetives famosos da literatura, como Miss Marple, ou Hercule Poirot, da Agatha Christie ou Auguste Dupin de Edgar Allan Poe. A análise dos resultados procura apresentar um novo olhar a respeito de metodologias de pesquisa, capaz de levantar e 


\section{MALANOVICZ}

motivar discussões interessantes na comunidade de pesquisa em Administração. Destaca-se, em especial, a inusitada contribuição que uma área como a Literatura pode oferecer para esta ciência. Vale lembrar que, segundo Sherlock Holmes, "o entrelaçamento de ideias oferece sempre um extraordinário interesse".

\section{Referências}

ALVES, L.R. Por um saber administrativo que compartilhe a história da cultura brasileira. In:

EnANPAD, 31, 2007, Rio de Janeiro: Anais... Rio de Janeiro: ANPAD, 2007.

BAÊTA, A.M.C. Saramago no ensino e aprendizagem de metodologia de pesquisa. In: DAVEL, E.;

VERGARA, S.C.; GHADIRI, D.P. (org.) Administração com arte. São Paulo: Atlas, 2007. (Capítulo 10).

BARDIN, L. Análise de Conteúdo. 3.ed. Rio de Janeiro: Edições 70, 2004.

BAUER, M.W.; GASKELL, G. Pesquisa Qualitativa com Texto, Imagem e Som. Petrópolis, RJ: Vozes, 2002.

BENBASAT, I.; GOLDSTEIN, D.; MEAD, M. The Case Research Strategy in Studies of Information Systems, MIS Quarterly, v.11, n.3, 1987, p.369-387.

BEST OF SHERLOCK. The Best of Sherlock Holmes: Beeton's Christmas Annual 1887. 2010.

Disponível em: http://www.bestofsherlock.com/index.htm Acesso em: 05 mar.2018.

BRYMAN, A.; CASSEL, C. The researcher interview: a reflexive perspective. Qualitative Research in Organizations and Management. v.1. n.1, 2006. p.41-55.

CAMDEN HOUSE. The Complete Sherlock Holmes. 2014. Disponível em:

http://ignisart.com/camdenhouse/canon/index.html Acesso em: 05 mar.2018.

CAMPBELL, D.T.; STANLEY, J.C. Delineamentos experimentais e quase-experimentais de pesquisa. São Paulo: EDUSP, 1979.

CARDOSO, R. Aventuras de Antropólogos em Campo ou Como Escapar das Armadilhas do Método. In: CARDOSO, R. (org.). A Aventura Antropológica: teoria e pesquisa. Rio de Janeiro: Paz e Terra, 1986. DENZLIN, N.K.; LINCOLN, Y.S. (eds.) Handbook of qualitative research. Newbury Park: Sage, 1994. DUBÉ, L.; PARÉ, G. Rigor in IS Positivist case research. MIS Quarterly, v.27, n.4, dec.2003, p.597-635. EnANPAD. EnEPQ: temas de interesse. 2018. http://www.anpad.org.br/ Acesso em: 05 mar. 2018. FISCHER, T.; DAVEL, E.; VERGARA, S.C.; GHADIRI, S.D. Razão e sensibilidade no ensino de administração: a literatura como recurso estético, In: EnANPAD, 30, 2006, Anais... Salvador: ANPAD, 2006.

FREITAS, H.; OLIVEIRA, M.; SACCOL, A.Z; MOSCAROLA, J. O método de pesquisa survey. Revista de Administração, v.35, n.3, jul./set.2000, p.105-112.

GEPHART Jr., R.P. Qualitative Research and the Academy of Management Journal. From the Editors. Academy of Management Journal, 2004, v.47, n.4, p.454-462.

HAIR, J.F.; BABIN, B.; MONEY, A.H.; SAMOUEL, P. Métodos de Pesquisa em Administração. Porto 


\section{MALANOVICZ}

Alegre: Bookman, 2005.

MALHOTRA, N.K. Pesquisa de Marketing: Uma orientação aplicada. Porto Alegre: Bookman, 2006.

MacNAGHTEN, P.; MYERS, G. Focus Group. In: SEALE, C. et al. (Eds.) Qualitative research practice. London: Sage, 2004. p.65-79.

MEREDITH, J.R.; RATURI, A.; AMOAKO-GYAMPAH, K.; KAPLAN, B. Alternative Research Paradigms in Operations. Journal of Operations Management, v.8, n.4, oct.1989, p.297-326.

PINHEIRO, I.A.; VIEIRA, L.J.M. Construindo as pontes entre saberes: da Literatura à Gestão. In: Congresso Virtual Brasileiro, 2008. Disponível em: www.convibra.com.br/2008/artigos/214_0.pdf Acesso em: 22 set.2015.

POZZEBON, M.; FREITAS, H. Pela aplicabilidade - com um maior rigor científico - dos estudos de caso em sistemas de informação. Angra dos Reis/RJ: Anais do 21. ENANPAD, Rio de Janeiro: ANPAD, 1997.

PRIOR, L. Documents. In: SEALE, C. et al. (Eds.) Qualitative research practice. London: Sage, 2004.

RAPLEY, R. Interviews. In: SEALE, C. et al. (Eds.) Qualitative research practice. London: Sage, 2004.

SERVA, M.; JAIME Jr., P. Observação Participante e Pesquisa em Administração: uma postura antropológica. Revista de Administração de Empresas (RAE), v.35, n.1, maio-jun. 1995, p.64-79.

SHERLOCK HOLMES MUSEUM. The Sherlock Holmes Museum. Disponível em: http://www.sherlockholmes.co.uk/home.htm Acesso em: 05 mar.2018.

SILVA, D.F. A Ciência em Sherlock Holmes. Revista Tessituras, n.1, Nova Friburgo, maio 2010.

Disponível em: http://www.docentesfsd.com.br/ Acesso em: 23set.2015.

SPRADLEY, J.P. The ethnographic interview. New York: Holt, Rinehart and Winston. 1979.

STAKE, R.E. Qualitative case studies. In: DENZIN, N.K.; LINCOLN, Y.S. (Eds.) The Sage Handbook of Qualitative Research: Third Edition. London: Sage, 2005. p.443-466.

STRINGER, E. Action research: a handbook for practitioners. Thousand Oaks: Sage, 2007.

SUTTON, R.I.; STAW, B.M. O que não é teoria, Revista de Administração de Empresas (RAE), v.43, n.3, jul./set.2003, p.65-84.

TEDLOCK, Barbara. Ethnography and Ethnographic representation. In: DENZIN, N.K.; LINCOLN, Y.S. (Eds.) Strategies of Qualitative Research. London: Sage, 2003. p.165-213.

THIOLLENT, M. Pesquisa-ação nas Organizações. São Paulo: Cortez, 2003.

VERGARA, S.C. Projetos e Relatórios de Pesquisa em Administração. 5.ed. São Paulo: Atlas: 2004.

YIN, R.K. Estudo de Caso: Planejamento e Métodos. 5.ed. Porto Alegre: Bookman, 2015. 


\section{ANEXO 1 - CORPUS DA PESQUISA: O CÂNONE SHERLOCKIANO}

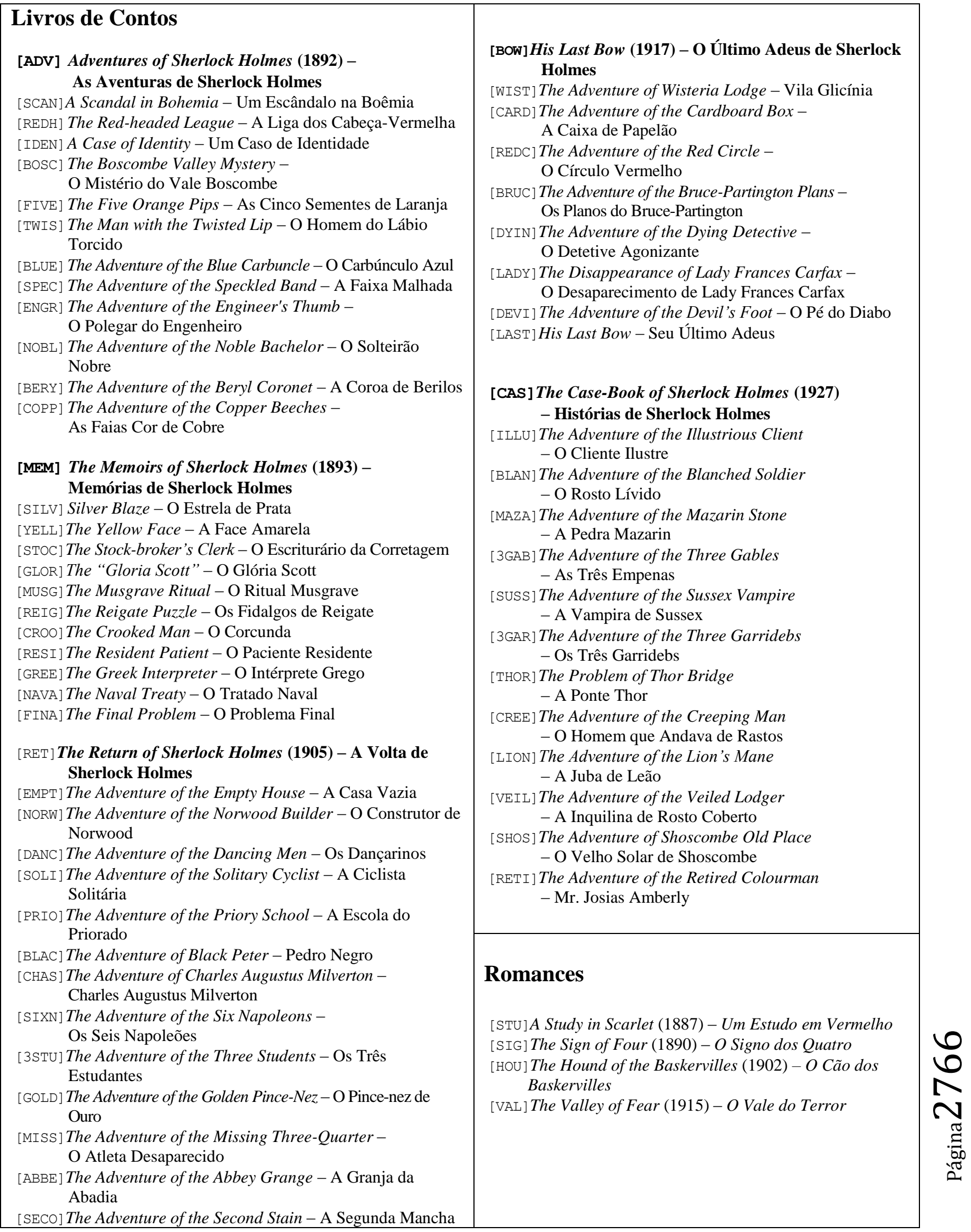

